\title{
Traumatic Subdural Hematoma and Intraparenchymal Contusion after a Firework Blast Injury
}

\author{
Luke GF Smith ${ }^{1 *}$, David Dornbos III ${ }^{1}$ and Jeffrey Leonard ${ }^{1,2}$ \\ ${ }^{1}$ Department of Neurological Surgery, The Ohio State University Wexner Medical Center, USA \\ ${ }^{2}$ Division of Pediatric Neurological Surgery, Nationwide Children's Hospital, USA
}

Submission: August 22, 2019; Published:October 30, 2019

*Corresponding author: Luke GF Smith, Department of Neurological Surgery, The Ohio State University Wexner Medical Center, Columbus, Ohio,

\begin{abstract}
Firework injuries represent a common etiology of injury requiring emergency department evaluation every year, especially in the pediatric population. Typically, firework-related injuries tend to produce burn or blast injuries; however, there have been no reports of fireworks causing an intracranial hematoma. The authors report a case of a consumer firework directly impacting the head of a 6-year-old boy, causing neurological deterioration. Trauma evaluation discovered a subdural hematoma, for which the child underwent emergency hemicraniectomy for surgical evacuation. Despite the injury, he recovered with minimal neurologic sequelae. After one month, he returned for cranioplasty and experienced a favorable outcome after his traumatic brain injury with some mild cognitive deficits.
\end{abstract}

Keywords: Fireworks; Subdural hematoma; Traumatic brain injury

Abbreviations: GCS: Glasgow Coma Score; CT: Computed Tomography;

\section{Introduction}

Firework displays are a frequently encountered and integral part of summertime holiday celebrations in the United States, although they do carry significant risk, especially in the pediatric population. Firework-related injuries comprise a small, yet significant, source of pediatric injury [1]. Since 1990, more than 5000 children were treated for consumer fireworkrelated injuries in emergency rooms across the United States on an annual basis [2]. In 2014 alone, 10,500 firework-related injuries required hospital treatment [3]. While orthopedic and burn injuries to the hands compose the majority of these injuries, $22.0 \%$ of firework-related injuries involve the head or neck [2]. Furthermore, a significant percentage of these injuries are suffered by bystanders [3]. A small fraction of these injuries require hospitalization, and even fewer require operative intervention $[4,5]$.

Pediatric brain injury due to projectile or explosive weapons in both civilian and military zones is well known [6-8]. While head injury caused by fireworks comprises approximately a fourth of all fireworks injury in children, there has not yet been a report in the literature of a firework impact causing an intracranial hemorrhage, much less an injury requiring emergency neurosurgical intervention. Herein we report a 6-year-old male bystander who suffered a consumer fireworkrelated blast injury, requiring emergent hemicraniectomy for evacuation of a subdural caused by the fireworks impact.

\section{Case Report}

\section{History and Examination}

A 6-year-old boy with no significant past medical history was at a neighborhood party celebrating Independence Day. The boy was a bystander in a crowd when a large firework misfired and hit the boy in the right temple. Per report, the firework exploded on or around the time of impact. The boy reportedly lost consciousness briefly and was then transported to our institution.

On initial presentation, the patient had a Glasgow Coma Score (GCS) of 14 with confusion regarding the year and his location, in addition to left lower extremity weakness. He had a $5 \mathrm{~cm}$ burn over his right temple with surrounding facial edema. Computed Tomography (CT) of the head demonstrated a $9 \mathrm{~mm}$ mixed-density right convexity subdural hematoma with 11 $\mathrm{mm}$ of midline shift (Figure 1). No skull fracture was identified 
(Figure 2). While in the trauma bay, he had a steady decline in consciousness. Due to the large subdural seen on imaging and concordant worsening exam findings, the decision was made to proceed with surgical intervention for evacuation of the hematoma (Figure 3).

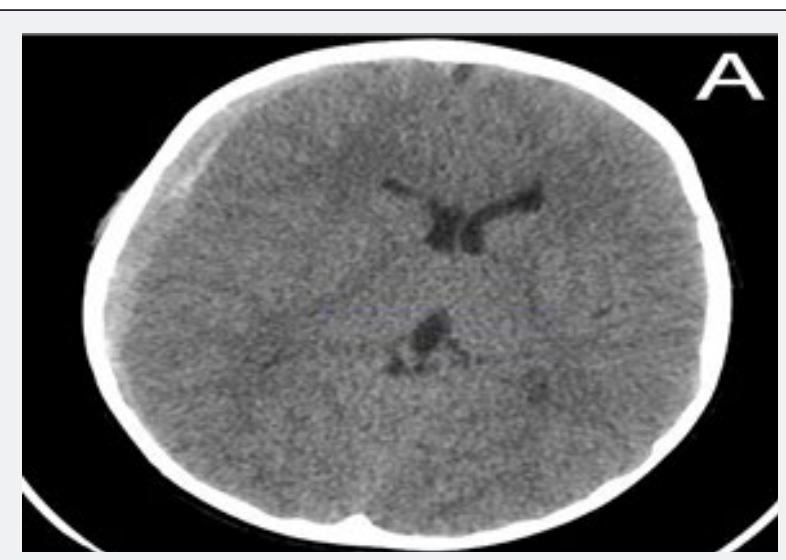

Figure 1: Radiographic evidence of blast injury secondary to a consumer firework. A. Axial CT of the head, demonstrating initial scan with a mixed-density right frontoparietal subdural hematoma with $11 \mathrm{~mm}$ midline shift.

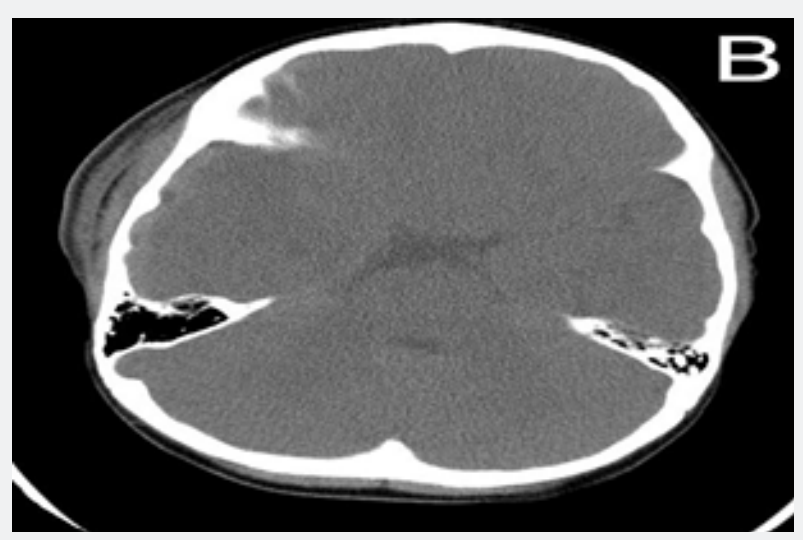

Figure 2: Axial head CT demonstrating soft tissue edema of the right temporal area without evidence of fracture

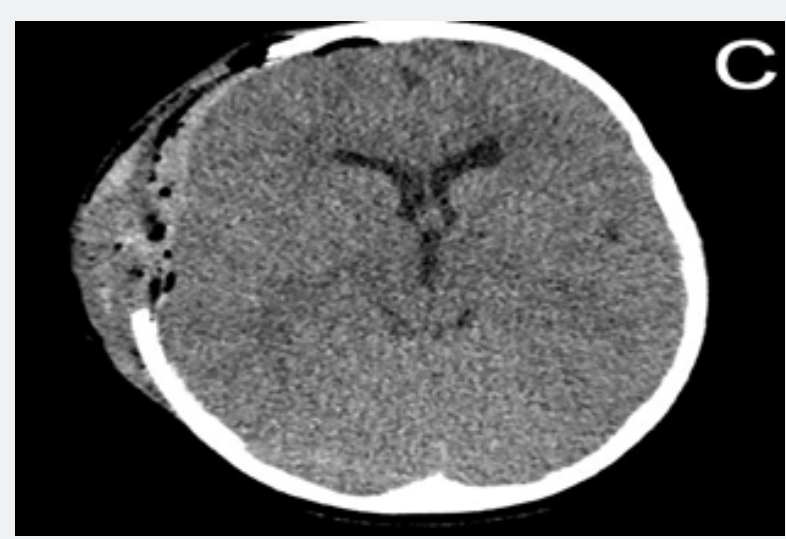

Figure 3: Axial head CT obtained post-operatively demonstrating craniectomy, evacuation of hematoma, and correction of midline shift

\section{Operation}

A right-sided front temporoparietal hemicraniectomy with evacuation of a significant subdural hematoma was performed.
A temporal parenchymal contusion was noted as the likely culprit of the subdural blood. Due to substantial cerebral edema, the bone flap was not immediately replaced. A right frontal 
intraparenchymal pressure monitor was placed, and he was taken to the Pediatric Intensive Care Unit post-operatively. A post-operative head CT was performed, showing satisfactory evacuation of subdural hematoma and markedly improved midline shift (Figure 4).

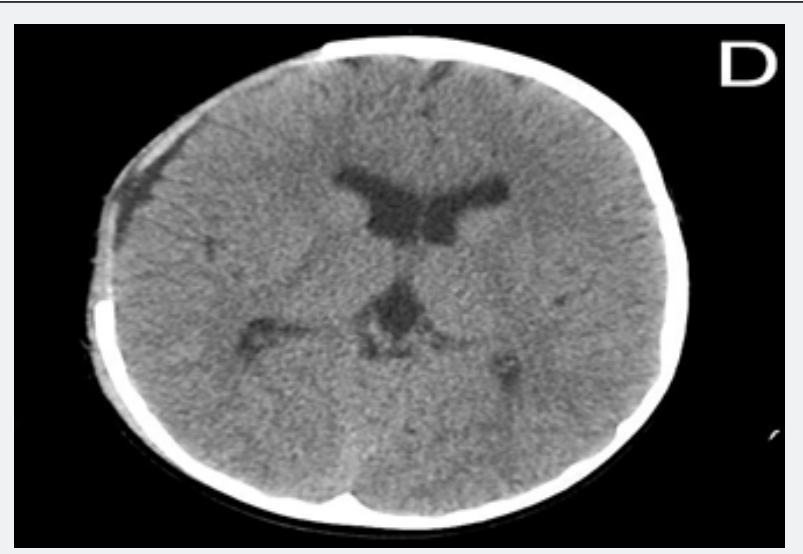

Figure 4: Axial head CT obtained post-operatively demonstrating craniectomy, evacuation of hematoma, and correction of midline shift

\section{Post-operative Course}

His post-operative course was uneventful. Intracranial pressure remained within normal limits, and he briskly followed commands. On the first day following surgery, the intraparenchymal pressure monitoring device was removed, and he was extubated. He progressed well and was discharged on post-operative day 5 . He returned 1 month after his initial injury for autologous cranioplasty and tolerated the procedure well without complications. At 5 months follow-up, he had returned to school with minor emotional outbursts and attention issues that were not present prior to injury.

\section{Discussion}

Fireworks, while a common part of many holiday celebrations in the United States, are an important etiology of pediatric injury. All common consumer fireworks have been known to cause injury, including death, incurring significant medical expenses [9]. However, significant firework-related neurological injury has not been previously reported in the literature. In the case discussed, we report a bystander child who incurred a serious neurological traumatic brain injury secondary to an aerial consumer firework used at a neighborhood firework display. Due to the severe injury, the child underwent a major surgery for evacuation of intracranial hematoma. Additionally, the patient required multiple days in the intensive care unit, required repeat admission for bone flap replacement, and had lasting cognitive effects.

Surprisingly, firework-related injuries to pediatric bystanders is reported in $26 \%$ of all fireworks injury cases [4]. Greater than half of the reported cases include adult supervision, demonstrating that even adult supervision does not necessarily prevent these types of injuries [4]. Public education initiatives about the dangers of fireworks have also failed to translate to meaningful changes in rates of pediatric fireworks injury [10]. The American Academy of Pediatrics has advocated for abolition of all consumer fireworks, encouraging attendance solely at public fireworks displays [11]. Given that consumer fireworks can cause pediatric head injury similar to that seen in weapon projectile or blast injury, as demonstrated in the case presented, this stance is reasonable [8].

Given the uncommon nature, traumatic brain injury secondary to cerebral blast injury may be missed on initial presentation, leading to a delay in diagnosis [12]. Recognition that consumer fireworks can cause these severe and potentially operative injuries is important in their overall treatment. The case reported here highlights the first reported case of severe traumatic brain injury and intracranial hemorrhage secondary to a firework-related injury, denoting the need for increased public knowledge of the danger of consumer fireworks.

\section{References}

1. (2001) American Academy of Pediatrics: Committee on I, Poison P: Fireworks-related injuries to children. Pediatrics 108: 190-191.

2. Berger LR, Kalishman S, Rivara FP (1985) Injuries from fireworks. Pediatrics 75(5): 877-882.

3. Billock RM, Chounthirath T, Smith GA (2017) Pediatric FireworkRelated Injuries Presenting to United States Emergency Departments, 1990-2014. Clin Pediatr (Phila) 56(6): 535-544.

4. Bochicchio GV, Lumpkins K, O'Connor J, Simard M, Schaub S, et al. (2008) Blast injury in a civilian trauma setting is associated with a delay in diagnosis of traumatic brain injury. Am Surg 74(3): 267-270.

5. D'Ippolito A, Collins CL, Comstock RD (2010) Epidemiology of pediatric holiday-related injuries presenting to US emergency departments. Pediatrics 125(5): 931-937.

6. Klimo P, Ragel BT, ScottWH, McCafferty R (2010) Pediatric neurosurgery during Operation Enduring Freedom. J Neurosurg Pediatr 6(2): 107114.

7. McFarland LV, Harris JR, Kobayashi JM, Dicker RC (1984) Risk factors 
for fireworks-related injury in Washington State. JAMA 251(24): 32513254 .

8. Quintana DA, Parker JR, Jordan FB, Tuggle DW, Mantor PC, et al. (1997) The spectrum of pediatric injuries after a bomb blast. J Pediatr Surg 32(2): 307-310

9. Smith GA, Knapp JF, Barnett TM, Shields BJ (1996) The rockets' red glare, the bombs bursting in air: fireworks-related injuries to children. Pediatrics 98(1): 1-9.

10. Tu Y, Granados, D (2015) 2014 Fireworks Annual Report: FireworksRelated Deaths, Emergency Department-Treated Injuries, and
Enforcement Activities During 2014, in. US Consumer Product Safety Commision p. 45.

11. Wani AA, Ramzan AU, Malik NK, Qayoom A, Nizami FA, et al. (2011) Missile injury to the pediatric brain in conflict zones. J Neurosurg Pediatr 7(3): 276-281.

12. Witsaman RJ, Comstock RD, Smith GA (2006) Pediatric fireworksrelated injuries in the United States: 1990-2003. Pediatrics 118(1): 296-303.

\section{Your next submission with Juniper Publishers} will reach you the below assets

- Quality Editorial service

- Swift Peer Review

- Reprints availability

- E-prints Service

- Manuscript Podcast for convenient understanding

- Global attainment for your research

- Manuscript accessibility in different formats ( Pdf, E-pub, Full Text, Audio)

- Unceasing customer service

Track the below URL for one-step submission https://juniperpublishers.com/online-submission.php 